\title{
Microarthropods and vegetation as biological indicators of soil quality studied in the poor sandy stand at former military sites
}

\author{
Iwona Gruss ${ }^{1}$, Jacek Twardowski ${ }^{1}$, Diana Nebeskáa ${ }^{2}$, Josef Trögl ${ }^{2}$, Tatyana Stefanovska ${ }^{3}$, \\ Valentina Pidlisnyuk ${ }^{2}$, and Iva Machová ${ }^{2}$ \\ ${ }^{1}$ Wrocław University of Environmental and Life Sciences \\ ${ }^{2}$ Jan Evangelista Purkyně University in Ústí nad Labem \\ ${ }^{3}$ National University of Life and Environmental Sciences of Ukraine
}

March 29, 2021

\begin{abstract}
Biota play major roles in soil function and are highly sensitive to any disturbances including land degradations. The objective of research was to evaluate the effectiveness of different methods used to determine soil quality in sandy soil, in particular to compare the microarthropod and vegetation indices. The following soil fauna indices were used: Collembola and Acari abundance, QBS-ar index, decomposition rate, feeding activity. The Ellenberg index was used as a vegetation indicator, in which the response to $\mathrm{pH}$, nutrients, and moisture was analysed. We based on an experiment conducted at a former military site in the Czech Republic. Soil quality was determined at two sites which differ slightly in nutrient content. Collembola abundance, feeding activity, and QBS-ar index were highly sensitive to minor differences in nutrients. In the group of vegetation indices, only the response to $\mathrm{pH}$ was significant. All analysed indices showed better biological quality in soils with higher nutrient content. Collembola were positively correlated with all vegetation indicators, which may indicate a close relation of springtails to certain plant species or similar habitat requirements. Finally, we indicate the usefulness of biological indicators for monitoring the quality of soil, which can be adopted when making various decisions concerning land use.
\end{abstract}

\section{Hosted file}

Main Document_Gruss et al to Land.pdf available at https://authorea.com/users/404695/ articles/515805-microarthropods-and-vegetation-as-biological-indicators-of-soil-qualitystudied-in-the-poor-sandy-stand-at-former-military-sites 

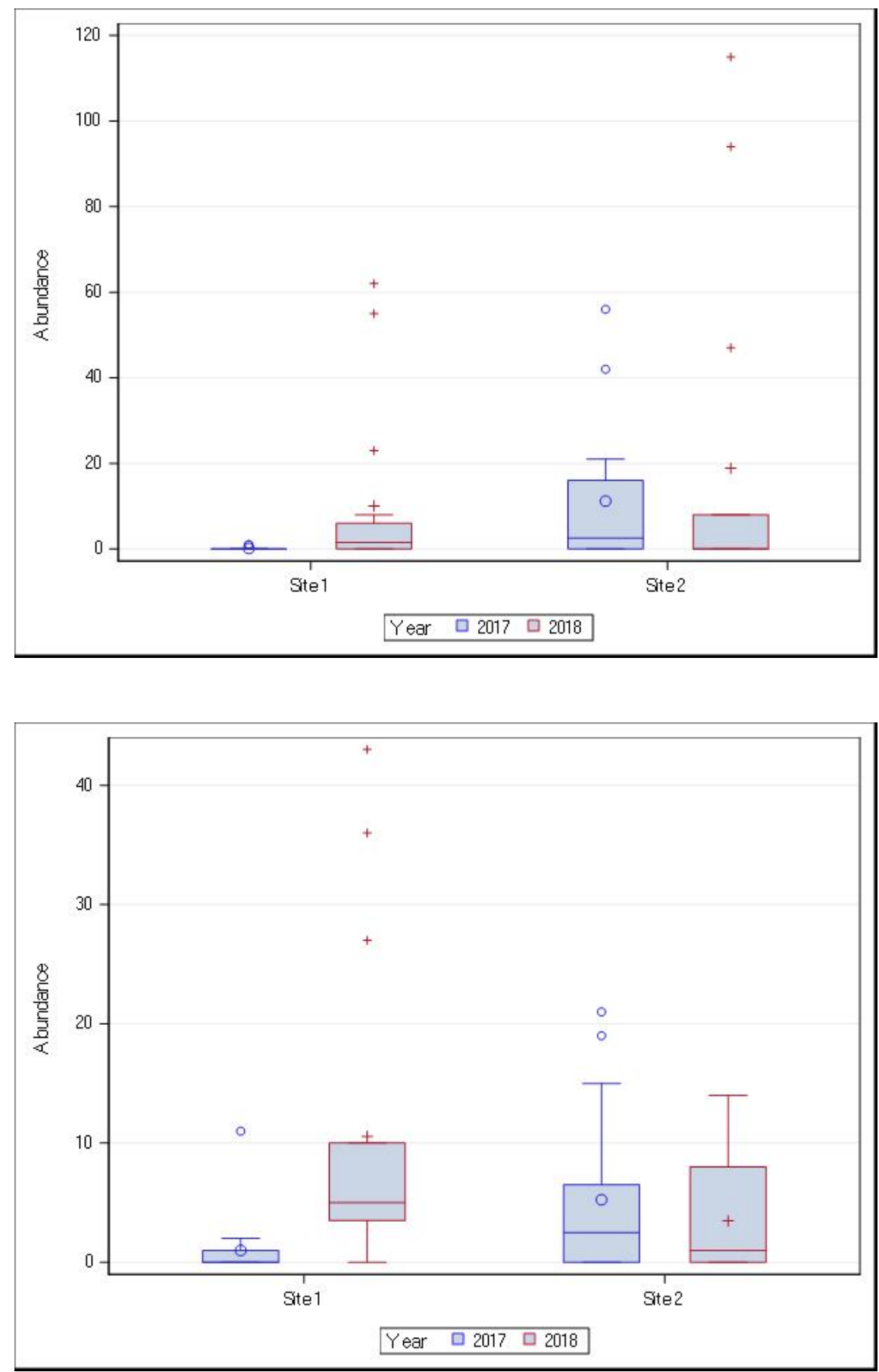

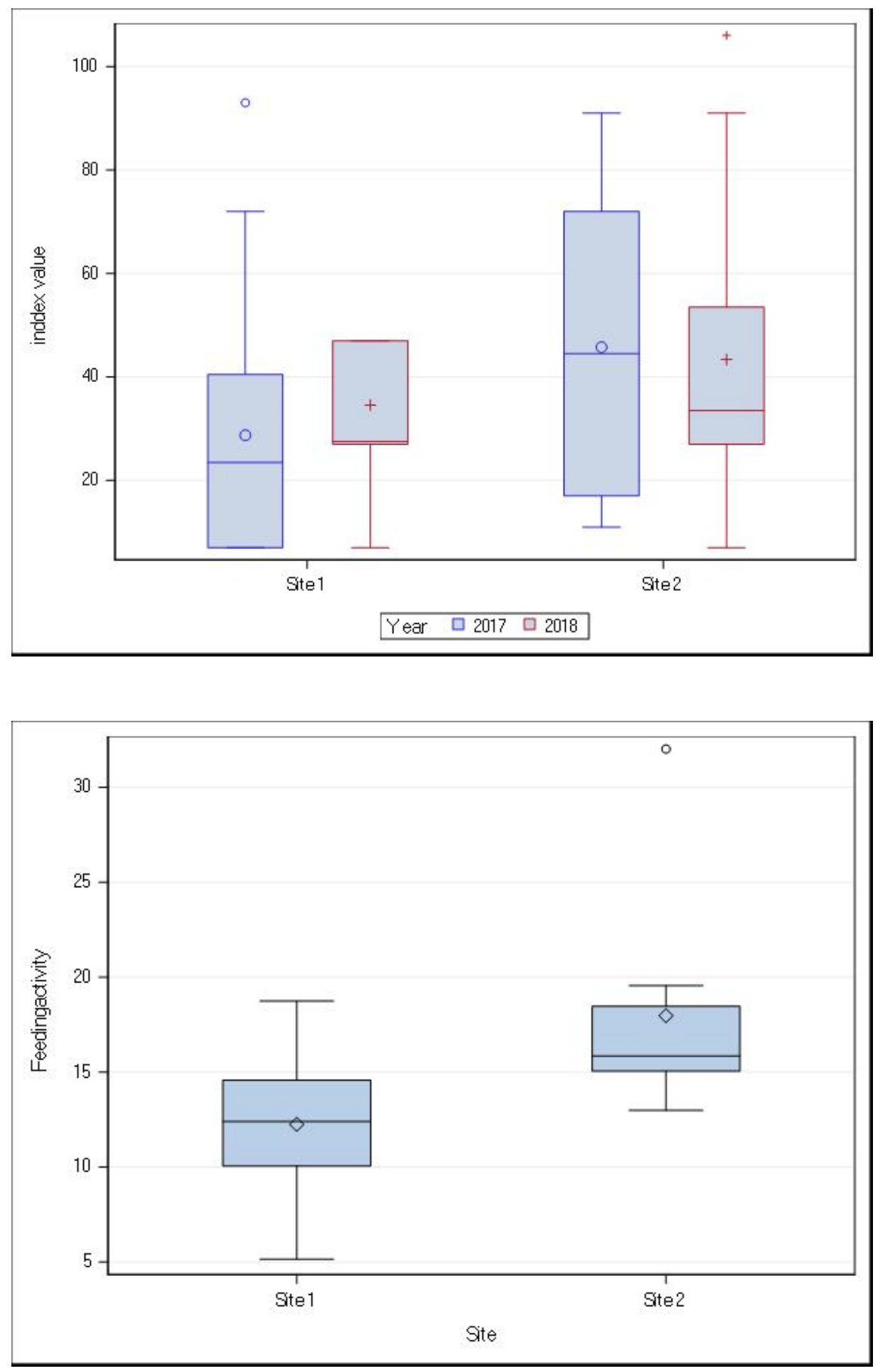

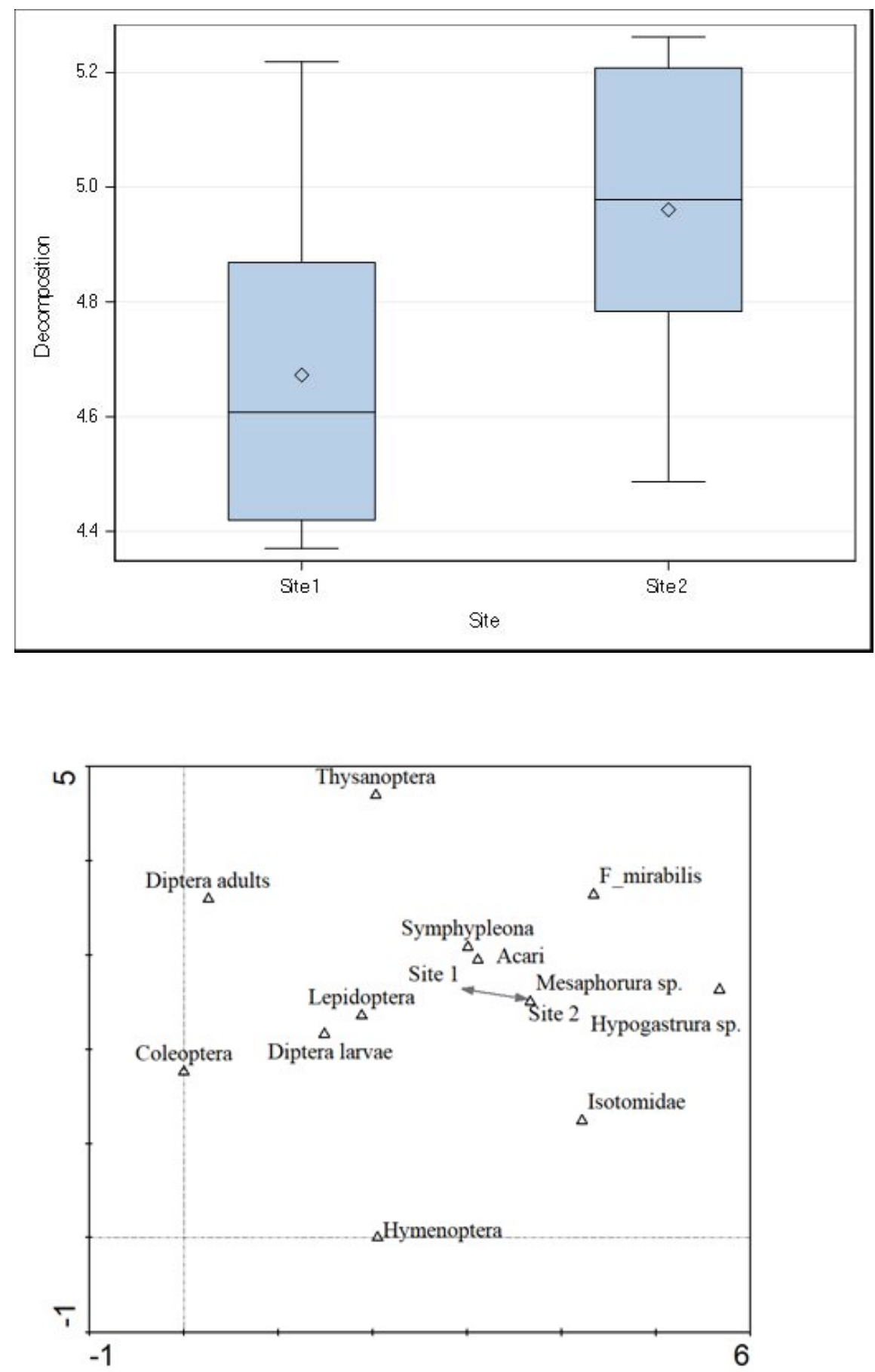


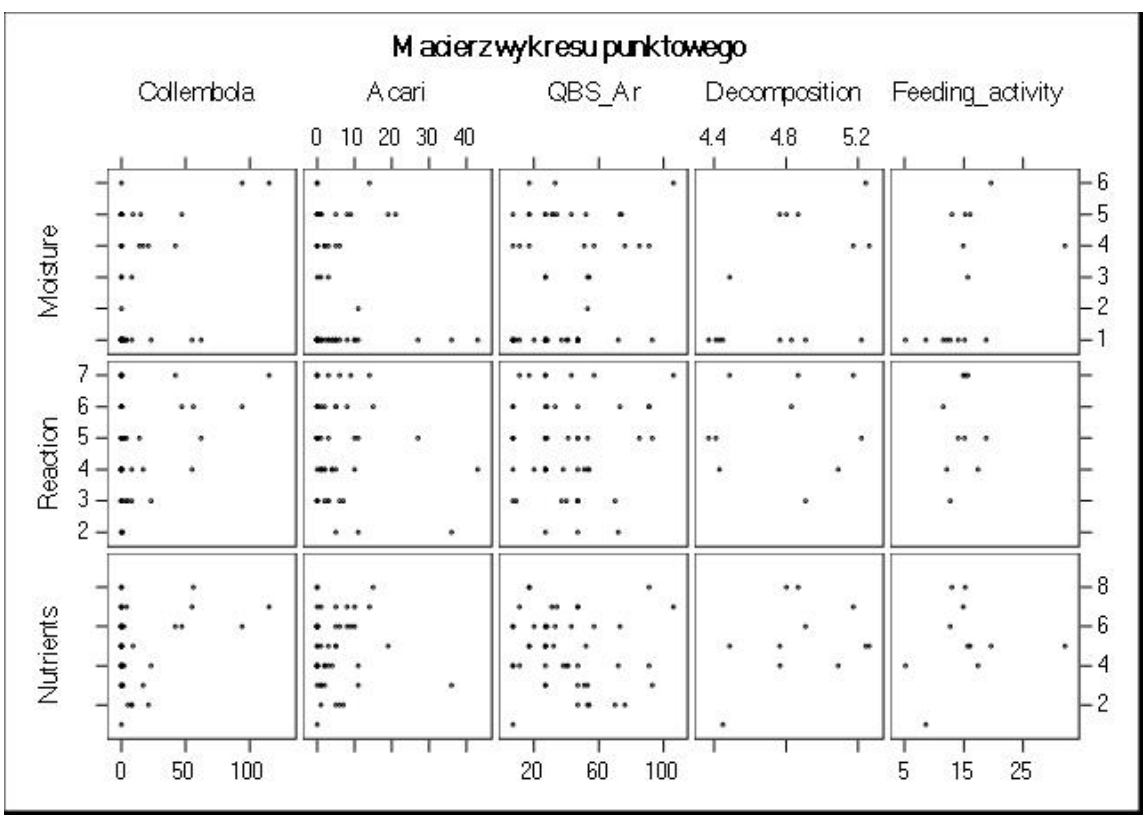

